University of Texas Rio Grande Valley

ScholarWorks @ UTRGV

\title{
An analogue study examining Attitude Change Theory and its implications for dissemination and implementation of empirically supported treatments
}

\author{
Laura D. Seligman \\ The University of Texas Rio Grande Valley, laura.seligman@utrgv.edu \\ Andrew L. Geers \\ Erin F. Swedish \\ Joseph D. Hovey \\ The University of Texas Rio Grande Valley, joseph.hovey@utrgv.edu \\ Gabriela Hurtado \\ Follow this and additional works at: https://scholarworks.utrgv.edu/psy_fac \\ Part of the Psychology Commons
}

\section{Recommended Citation}

Department of Psychological Science, The University of Texas Rio Grande Valley, Edinburg, TX 78539, Seligman, L., Geers, A., Department of Psychology, University of Toledo, Toledo, OH 43606, Swedish, E., Department of Gastroenterology, Boston Children's Hospital, Boston, MA 02115, Hovey, J., Department of Psychological Science, The University of Texas Rio Grande Valley, Edinburg, TX 78539, Hurtado, G., \& Steve Hicks School of Social Work, The University of Texas at Austin, Austin TX 78712. (2018). An analogue study examining Attitude Change Theory and its implications for dissemination and implementation of empirically supported treatments. Journal of Evidence-Based Psychotherapies, 18(2), 77-96. https://doi.org/10.24193/jebp.2018.2.15

This Article is brought to you for free and open access by the College of Liberal Arts at ScholarWorks @ UTRGV. It has been accepted for inclusion in Psychological Science Faculty Publications and Presentations by an authorized administrator of ScholarWorks @ UTRGV. For more information, please contact justin.white@utrgv.edu, william.flores01@utrgv.edu. 


\title{
AN ANALOGUE STUDY EXAMINING ATTITUDE CHANGE THEORY AND ITS IMPLICATIONS FOR DISSEMINATION AND IMPLEMENTATION OF EMPIRICALLY SUPPORTED TREATMENTS
}

Laura D. SELIGMAN ${ }^{1 *}$, Andrew L. GEERS ${ }^{2}$, Erin F. SWEDISH ${ }^{3}$, Joseph D. HOVEY ${ }^{1}$, Gabriela HURTADO

${ }^{1}$ Ph.D. ABPP, Department of Psychological Science, The University of Texas Rio Grande Valley, Edinburg, TX 78539

${ }^{2}$ Ph.D., Department of Psychology, University of Toledo, Toledo, $\mathrm{OH} 43606$

${ }^{3}$ Ph.D., Department of Gastroenterology, Boston Children's Hospital, Boston, MA 02115

${ }^{4}$ Ph.D., Steve Hicks School of Social Work, The University of Texas at Austin, Austin TX 78712

\begin{abstract}
Despite the promise of research-based treatments, dissemination into community settings has been problematic. Attitudes toward these treatments may be partially responsible for the slow uptake. Building on the functional theory of attitudes, it was hypothesized that presenting emotion-focused rather than cognitively-focused information about a treatment would produce more positive attitudes toward the treatment in individuals interested in clinical practice. To test this hypothesis, 144 students (116 women; $\mathrm{M}_{\mathrm{age}}=22.46$ years) completed a measure of vocational interest and evaluated a treatment after reading either an emotional or cognitive passage about the treatment. Consistent with the hypothesis, participants' interests in clinical activities were related to more favorable reactions to the emotional passage but not the cognitive passage. This effect was partially mediated by message elaboration. Findings suggest that presenting clinicians with emotionally rich information on treatment options may help bridge the gap between research and practice.
\end{abstract}

Keywords: evidence-based practice, empirically supported treatments, dissemination, persuasion, elaboration likelihood model

\footnotetext{
* All correspondence regarding this article should be sent to Laura D. Seligman, Department of Psychological Science, University of Texas Rio Grande Valley, Edinburg, TX 78539. 1.956.665.2866.
} 


\section{An Analogue Study of the Implications of Message Matching for the Dissemination of Empirically Supported Treatments}

Dozens of empirically supported treatments $(\mathrm{ESTs})^{*}$ for the treatment of psychological disorders have been identified for adults as well as children, adolescents, families, and couples (Chambless \& Ollendick, 2001; Chorpita et al., 2011; DeRubeis \& Crits-Christoph, 1998; Higa-McMillan, Francis, Rith-Najarian, \& Chorpita, 2016). However, research suggests that these treatments are not as commonly used in routine clinical practice as would be expected (Barlow, Levitt, \& Bufka, 1999; Borntrager, Chorpita, Higa-McMillan, Daleiden, \& Starace, 2013; Stewart \& Chambless, 2007). So, while much work remains to be done developing and refining treatments, efforts have also begun to focus on how to disseminate the current knowledge base in a way that leads to the effective implementation of empirically supported treatments in routine practice.

Traditional approaches for treatment dissemination have focused on the transfer of knowledge from research settings to clinical practice; more recently, however, there has been a call for dissemination and implementation strategies that address practitioners' attitudes and intentions as well as knowledge acquisition (e.g., Chorpita \& Regan, 2009). This change in approach can be attributed to two bodies of research. First, multiple studies find little change in therapist behavior after traditional approaches to training - even when knowledge increases (JensenDoss, Cusack, \& de Arellano, 2008; Lopez, Osterberg, Jensen-Doss, \& Rae, 2011). Second, several studies have found that clinicians often have unfavorable attitudes toward research-based treatments (Aarons, 2004; Barlow et al., 1999; Borntrager et al., 2013; Deacon, Farrell, et al., 2013; Deacon, Lickel, Farrell, Kemp, \& Hipol, 2013; Seligman et al., 2016). Importantly, it may be that these unfavorable attitudes can help explain the relative lack of use of empirically supported treatments in many clinical settings in that attitudes are closely linked to behavioral intent (Ajzen, 1991) and often to actual behavior (Petty \& Wegener, 1999). Thus, a better understanding of the basis for these attitudes and the factors relevant for successful attitude change is required. However, despite research and theory suggesting that attitudes can be a primary force driving behavior, relatively few studies have focused on attitudes and their relevance for the adoption or nonadoption of ESTs. Those studies that do examine attitudes toward ESTs are often descriptive and few have drawn from the basic science of attitude change and

\footnotetext{
* The terms empirically supported treatment and evidence based practice are often used interchangeably; however, evidence based practice refers to "the integration of the best available research with clinical expertise in the context of patient characteristics, culture, and preferences" (APA Presidential Task Force on Evidence-Based Practice, 2006, p. 273) while an empirically supported treatment is a treatment that has been shown to be "efficacious in controlled research with a delineated population" (Chambless \& Hollon, 1998, p. 7). Therefore, we specifically use the term EST here to refer to a research-based treatment.
} 
persuasion (see however, Farrell, Deacon, Dixon, \& Lickel, 2013). The studies that indirectly address clinician attitudes (e.g., providing training in ESTs to promote their use) adopt an implicit theory of attitude change, that attitudes are formed and changed strictly on rational grounds, that runs counter to much of what we know about attitudes and attitude change.

\section{Determinants of Attitudes}

Early theories of attitudes recognized that attitudes are not simple linear representations of the available data. For example, Katz (1960) proposed a functional approach to attitudes which suggests that attitudes can serve different functions both within and across individuals and that these functions need to be taken into account when designing attitude change interventions. More recently, dual systems theories suggest that we rely to varying degrees on two different systems as the basis for our attitudes - one system is fast and uses heuristics, relying more heavily on intuition and emotional connections; the second system is slow and deliberate and relies more heavily on rational analysis (Chaiken \& Trope, 1999; Evans, 2008; Strack \& Deutsch, 2004). While everyone uses both systems when forming an attitude, the degree to which one relies on one system versus the other has been shown to vary across individuals. In fact, these theories suggest that information aimed at persuading an individual (e.g., training on an EST along with the data to support its use) may be perceived very differently depending on the characteristics the individual brings to the situation; consequently, persuasive messages must be tailored to match the basis of the individual's attitude to be maximally effective. More explicitly, Zajonc and Markus (1982) state

To change an attitude that has evolved primarily from affective sources and so has considerable extracognitive supports, may require methods different from those needed to change an attitude based on cognition; it may require an attack on the affective basis of preference. (p.127)

Research testing this matching hypothesis has been largely supportive. For example, Edwards (1990) examined the effects of matching affective and cognitive persuasive messages to affective or cognitively based attitudes and found that matching the message to the basis of the attitude was more effective when the attitude was more affectively based. Interestingly, however, in this experiment cognitively-based attitudes seemed equally open to affective and cognitive methods of persuasion. Furthering this line of research, in a series of two experiments Edwards and von Hippel (1995) examined attitudes that were primarily affective or cognitive but were more representative of the hybrid conditions that typify most real attitudes. Importantly, these experiments focused on changing attitudes toward a familiar and complex object (i.e., a person) much like the types of attitudes that 
are often the focus of persuasion attempts in real world settings (e.g., a new treatment being proposed for adoption by clinicians). In the first experiment, participants received affective information (a photograph) and cognitive information (a portfolio) about a presumable job applicant. All participants received both types of information but the order of the presentation was varied given that it is believed that initial information provides a stronger basis for an attitude (Anderson, 1971; Asch, 1946). Then, a persuasive appeal with negative information to challenge this initial attitude toward the "job applicant" was presented. The cognitive persuasion attempt involved giving the participants access to applicants' responses to a series of interview questions. The fictitious responses presented the applicant in a mildly negative light. The affective persuasion attempt involved an "accidental" exposure to the job applicant (a confederate) in which the applicant was disheveled and ignored the participant. Again, all participants received both types of information; only the order was varied, depending upon condition. Matched messages produced significantly larger changes in attitudes for those in the affective attitude condition. A trend toward this matching effect was found for the cognitive attitude group but the effect did not reach the level of statistical significance. Experiment 2 extended these findings by using different methods of attitude induction and persuasion in order to show that the effects in Experiment 1 were not due to the specific methodology used. Again, the matching effect was found but interestingly, again matching was mostly relevant when attitudes were affectively based. Theory suggests that this stronger matching effect for affective attitudes may occur because affective attitudes tend to be unidimensional whereas cognitive attitudes tend to be multidimensional; therefore, matching a cognitive message might be more difficult, requiring that the specific dimensions or beliefs on which the attitude is based are targeted (Drolet \& Aaker, 2002). In summary, this series of experiments suggest that matching persuasive attempts to attitude functions can be important even when the attitude object is relatively complex and familiar but that this is may be more easily done when the attitude serves an emotional function.

Thus, persuasion research suggests that attempts to change attitudes toward ESTs would be enhanced by knowledge about the basis of these attitudes and specifically, whether the individual's attitude toward ESTs is based primarily on cognition or emotion. This may be problematic, however, in that although there have been some attempts to measure attitude functions (see for example, Herek, 1987), research suggests that people are often inaccurate in reporting on the basis for their attitudes and that introspection may lead to enhanced inaccuracy (Wilson \& Dunn, 1986). Therefore, much of the research in this area has focused on a less direct route to predicting attitude function - examining dispositional differences in attitude formation. 


\section{Dispositional Differences in Attitude Bases}

The tendency to form attitudes with a cognitive versus affective basis appears to be fairly stable (Huskinson \& Haddock, 2004) with the tendency to form attitudes with an affective basis related to one's chronic level of need for affect (NFA) and reliance on intuition whereas the tendency to form attitudes with a cognitive function may be related to chronic levels of need for cognition (NFC) (Haddock, Maio, Arnold, \& Huskinson, 2008; Huskinson \& Haddock, 2004). Importantly, support has been found for the matching hypothesis when a persuasive message has been matched to one's tendency toward affective versus cognitive attitudes (Haddock et al., 2008). More specifically, it has been found that affective appeals produce more positive attitudes in those who are high in NFA but low in NFC and cognitive appeals produce more positive attitudes in those high in NFC and low in NFA (Haddock et al., 2008, study 1). Moreover, NFA has been related to response to an affective appeal but not to response to a cognitive appeal whereas NFC has been related to response to a cognitive appeal but not an affective appeal (Haddock et al., 2008, study 2).

The relationship between NFC, NFA, reliance on intuition and attitude basis may be particularly relevant when considering clinicians' attitudes toward ESTs in that both theory and research suggest that clinicians may generally have relatively high NFA and they tend to favor an intuitive decision-making style. For example, surveys have found that clinicians report a preference for using intuitive processes in their work (Stewart \& Chambless, 2007). Additionally, as far back as the late 1970s, it was proposed that psychologists choosing an academic or research-oriented career may do so in part because of their preference for analytical processes whereas those who are more clinically focused may have a worldview more focused on emotion (Gelso, 1979). There has been some empirical support for this notion. For example, Leong and colleagues found that NFC was positively related to self-reported interest in scientific activities amongst a sample of 100 undergraduate psychology majors with the intention of attending graduate school; on the other hand, NFC was not correlated with interest in clinical activities (Leong, Zachar, Conant, \& Tolliver, 2007). More recently, Seligman et al. (2016) found that clinical psychologists who chose an academic/research career reported higher NFC compared to those choosing a practice-oriented career; on the other hand, psychologists engaged primarily in clinical practice reported greater reliance on intuitive decision-making relative to those in research careers. These characteristics were in fact related to attitudes toward the use of ESTs. It should also be noted that the benefits of reliance on affect and intuition in complex situations, like those clinicians encounter in everyday patient interactions, has been supported by research (de Vries, Witteman, Holland, \& Dijksterhuis, 2010; Dijksterhuis \& Nordgren, 2006), suggesting that this is a skill that must be developed in clinical practice and one that would likely be reinforced. Taken 
together, this indicates that information about clinical practice should be tailored to the ways clinicians need to work and process information in their everyday activities.

\section{The Current Study}

Based on early theory and recent findings on the relationship between interest in clinical activities, NFA, and intuitive decision-making style as well as the link between these dispositional characteristics and emotionally based attitudes, an analogue study was conducted to test the hypothesis that individuals with greater interest in practice activities would view information about a treatment more favorably when presented with an emotionally-based appeal. In addition, two competing hypotheses have been put forward to explain why such matching effects occur, one derived from the elaboration likelihood model (ELM; Petty \& Cacioppo, 1981; Petty \& Cacioppo, 1986; Petty \& Wegener, 1998) and the other from the fluency model (Mayer \& Tormala, 2010). The ELM suggests that matched messages result in increased motivation on the part of the receiver due to their personal relevance. This means the receiver will spend more effort to scrutinize or elaborate on a matched message; thus, if the message presents a strong case, this will be adequately processed by the recipient. The fluency hypothesis suggests that message matching causes one to perceive the information as familiar and therefore easier to process; this subjective positive feeling results in greater persuasion. Thus, a secondary goal of the current study was to examine whether elaboration, fluency, or both elaboration and fluency serve as mediators of the matching effect.

\section{Method}

\section{Participants and Design}

Previous research has examined samples ranging from 24 participants to over 200 (Clarkson, Tormala, \& Rucker, 2011; Edwards \& Vonhippel, 1995; Fazio \& Williams, 1986), with the most closely matched studies including sample sizes of 115 and 125 (Clarkson et al., 2011). Given that we hypothesized an interaction and wanted to examine mediation, we estimated we needed a sample size of around 150 participants for adequate power; we were able to obtain a sample close to this goal. Participants were 144 students (28 men; 116 women) enrolled in an introductory psychology course in a large Midwestern university in the United States. All participants provided informed consent. Two participants did not report their age; for those with available data the mean age was 22.46 years $(S D=4.32$, range $18-49)$. The majority of the sample (76\%) were Caucasian, $14 \%$ were Black/African 
American, 4\% were Hispanic/Latino, 4\% were Arab Americans, $1 \%$ were Native American, and $1 \%$ indicated they identified with some other ethnic group. Other than being enrolled in introductory psychology, the only other inclusion/exclusion criterion was that participants needed to be at least 18 years of age.

An attribute treatment interaction design was used in which the attribute of interest was participants' interest in clinical practice and the "treatment" was the type of appeal (emotional versus cognitive). Interest in clinical practice was measured as described below. Participants were randomly assigned to read either an emotional message $(n=65)$ or cognitive message $(n=79)$ using Psychdata's (Locke \& Keiser-Clark, 2001) simple randomization procedure. Demographic characteristics of the two groups are presented in Table 1.

Table 1. Demographic characteristics of sample, by condition.

\begin{tabular}{|r|r|r|}
\hline & $\begin{array}{c}\text { Emotional Message } \\
(\mathrm{n}=65)\end{array}$ & $\begin{array}{c}\text { Cognitive Message } \\
(\mathrm{n}=79)\end{array}$ \\
\hline Gender $N(\%)$ & & $15(19 \%)$ \\
\hline Female & $13(20 \%)$ & $64(81 \%)$ \\
\hline Male & $52(80 \%)$ & $22.28(3.62)$ \\
\hline Race $N(\%)$ & $22.70(5.08)$ & $0(0 \%)$ \\
\hline American/Indian & & $4(5 \%)$ \\
\hline Arab American & $1(1.5 \%)$ & $7(8.9 \%)$ \\
\hline Black or African American & $1(1.5 \%)$ & $64(81.0 \%)$ \\
\hline White/Caucasian & $13(20 \%)$ & $3(3.8 \%)$ \\
\hline Hispanic/Latino & $46(71 \%)$ & $1(1.3 \%)$ \\
\hline Other & $3(4.6 \%)$ & $1(1.5 \%)$ \\
\hline
\end{tabular}

\section{Procedure}

Predictor/Independent measures and manipulation check.

Message. Both messages described a fictional treatment for avoidant personality disorder ${ }^{1}$ and the costs and benefits of said treatment. The cognitive message included statements and simple statistics (i.e., percentages) from fictional research studies conducted with people who had undergone the treatment for avoidant personality disorder (e.g., the treated group had a higher income). The emotional message included persuasive statements that highlighted and used emotional language (e.g., pride, hope) and emphasized the emotional repercussions

\footnotetext{
${ }^{1}$ Avoidant personality disorder was chosen because we believed that few students would have extensive information on this disorder or its treatment.
} 
of the treatment for an individual; it did not include any reference to research findings. As an example of the information provided, the emotional paragraph included a statement about an individual's pride when he began dating after completing the treatment; the cognitive paragraph compared (favorably) the percentage of people who completed the treatment who began dating as compared to a no treatment control. The cognitive and emotional passages were matched on approximate reading level and length.

Interest in clinical practice activities. The Scientist Practitioner Inventory (SPI; Leong \& Zachar, 1991) is a 42 item self-report questionnaire designed to measure interest in clinical practice and clinical science. The instrument consists of two scales - a 21 item scientist interest scale and a 21 item practitioner interest scale. Each item asks respondents to indicate how much interest they have in a given activity (e.g., "Conducting a psychotherapy session with an individual client" or "Collecting data on a research project you designed"), using a 1 (very low interest) to 5 (very high interest) Likert scale. As such, scores on each of the SPI scales can range from 21 (very low interest) to 105 (very high interest). The authors of the SPI report excellent internal consistency of the two scales $(>.90)$ across several student samples that included undergraduate students, graduate students, psychology majors and non-psychology majors (Leong \& Zachar, 1991). In addition, they report evidence of adequate test-retest reliability and concurrent validity. The SPI practitioner scale score was used here to assess students' practitioner orientation. As with previous research, the internal consistency of the practitioner scale in our sample was high $(\alpha=.94)$. Students' scores ranged from 21 to 97 , with a mean of $63.60(S D=17.04)$, suggesting moderate levels of interest in clinical activities on average, with the sample covering almost the full range from very low to very high interest.

Manipulation check item. To examine whether the manipulation was effective, participants were asked to indicate whether the passage they read was more focused on facts and logic or experiences and emotions.

\section{Dependent and Mediator Measures}

Attitudes. Participants' evaluation of the treatment was assessed with a 14item measure designed for this study. Respondents used a 9-point Likert scale to rate their attitudes toward the treatment, with higher scores indicating more favorable attitudes. For example, respondents were asked to rate the quality of the treatment, its drawbacks, and its importance for people with avoidant personality disorder $^{2}$. The items in the measure demonstrated very high internal consistency ( $\alpha$ $=.94$ ) so an overall therapy evaluation score was created by averaging participants' responses across the 14 items.

\footnotetext{
${ }^{2}$ A complete list of items is available from the authors.
} 
Behavioral Evaluation. In order to assess participants' attitudes toward behaviors related to the use of the treatment, participants were asked to indicate the likelihood that they would choose the treatment they read about if they needed treatment for avoidant personality disorder. They responded using a 9-point likert scale with higher scores indicating greater willingness to consider the treatment.

Elaboration. Two items assessed message elaboration. Participants used a 9-point likert scale to indicate how much the message made them think and how interested they were in the message. Responses on these two items were highly correlated $(r=.63, p<.0001)$ so responses were averaged to arrive at a single measure of elaboration.

Fluency. Based on procedures used by Mayer and Tormala (2010), participants were asked to provide a rating of how easy (1) to hard (9) the message was to read using a 9-point Likert scale. Lower ratings indicated greater ease or higher fluency.

\section{Results}

All analyses were conducted in SPSS version 24 (IBM Corp, Released 2016).

\section{Manipulation Check}

A chi-square analysis revealed a significant association between message condition and whether participants identified the passage they read as focused primarily on facts and logic or experiences and emotions $\left(\chi^{2}(1, n=144)=33.11, p\right.$ $<.001)$. Participants in the emotional condition were more likely to indicate the passage they read focused on experiences and emotions and the participants in the cognitive message condition were more likely to indicate that the message they read focused more on facts and logic.

\section{Evaluation of the Treatment}

It was hypothesized that those participants who reported greater interest in practice activities would report more favorable opinions of the hypothetical treatment when they were presented with the emotional message but not when they were presented with the cognitive message. To test this hypothesis, a simultaneous regression analysis was performed in which message type, practitioner orientation (centered around the mean), and the practitioner orientation $\mathrm{X}$ message type interaction, were regressed on the attitudes toward treatment measure. As expected, there was no main effect for message type, $\beta=.06, p>.05$. There was a main effect for practitioner orientation $(\beta=.30, p<.05)$; however, this was qualified by the predicted message type $\mathrm{X}$ practitioner orientation interaction, $\beta=.26, p<.05$. 
Simple slopes analyses revealed that participants with a higher practice orientation reported more favorable attitudes toward the treatment when they received an emotional message, $t(140)=2.47, p<.05$, but that practitioner orientation scores were not significantly related to attitudes toward the cognitive message, $t(140)=-$ $0.44, p>.05$ (see Figure 1).

Figure 1. Predicted values for attitudes toward treatment as a function of practitioner orientation scores and message condition.

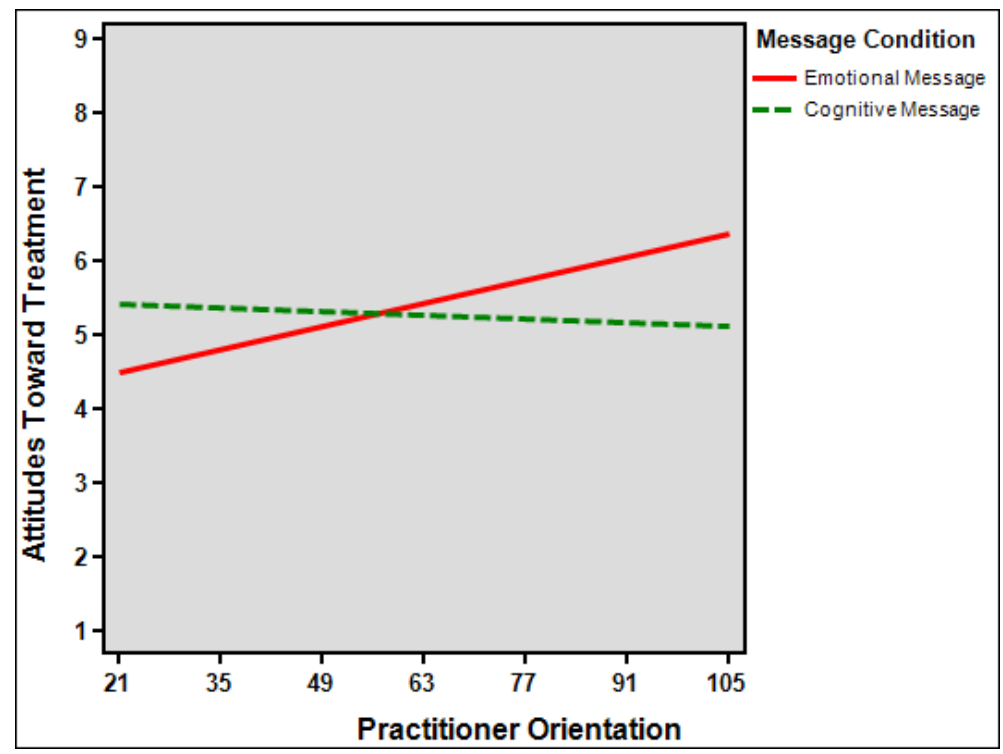

\section{Mediation Analyses}

In order to test the hypotheses that elaboration and/or fluency mediated the message matching effects, a mediation analysis was conducted using a bootstrapping approach to examine fluency and elaboration simultaneously (Preacher \& Hayes, 2008). More specifically the 95\% bias corrected confidence intervals (CIs) around the indirect effects were computed. A CI not including 0 is indicative of mediation. Results revealed that elaboration (95 CI\% $=-0.0249$ to .0006 ) but not fluency ( $95 \mathrm{CI} \%=-.0074$ to .0024 ) mediated the relationship between the condition $\mathrm{X}$ practitioner interaction and attitude toward therapy while controlling for the main effects of condition and practitioner orientation.

Analysis of the component paths suggests that the message type $\mathrm{X}$ practitioner orientation interaction had a significant effect on fluency $t=2.00, p<.05$; whereas the effect on elaboration approached significance $t=1.79, p=.08$. Fluency did not have a direct effect on evaluation of the treatment $t=0.59, p>.05$ but the effect of elaboration on evaluation of the treatment was significant $t=7.19, p<.001$. 


\section{Behavioral Evaluation}

Message type, practitioner orientation, and the practitioner orientation $\mathrm{X}$ message type interaction were regressed on participants' ratings of the likelihood they would choose the fictional treatment if needed. As with participants attitudes, there was no main effect for message type $(\beta=.08, p>.05)$ but there was a main effect for practitioner orientation $(\beta=.32, p<.05)$. Again, however, this was qualified by the predicted message type $\mathrm{X}$ practitioner orientation interaction $(\beta=$ $.28, p<.05)$. Simple slopes analyses again suggest that the interaction was driven by reactions to the emotional message. That is, participants with more of a practice orientation indicated they were more likely to choose the proposed treatment when they received the emotional message, $t(140)=2.62, p<.05$, but that practitioner orientation did not have a significant effect on behavioral evaluations when participants were presented with the cognitive message, $t(140)=-0.56, p>.05$ (see Figure 2).

Figure 2. Predicted values for behavioral evaluations as a function of practitioner orientation scores and message condition.

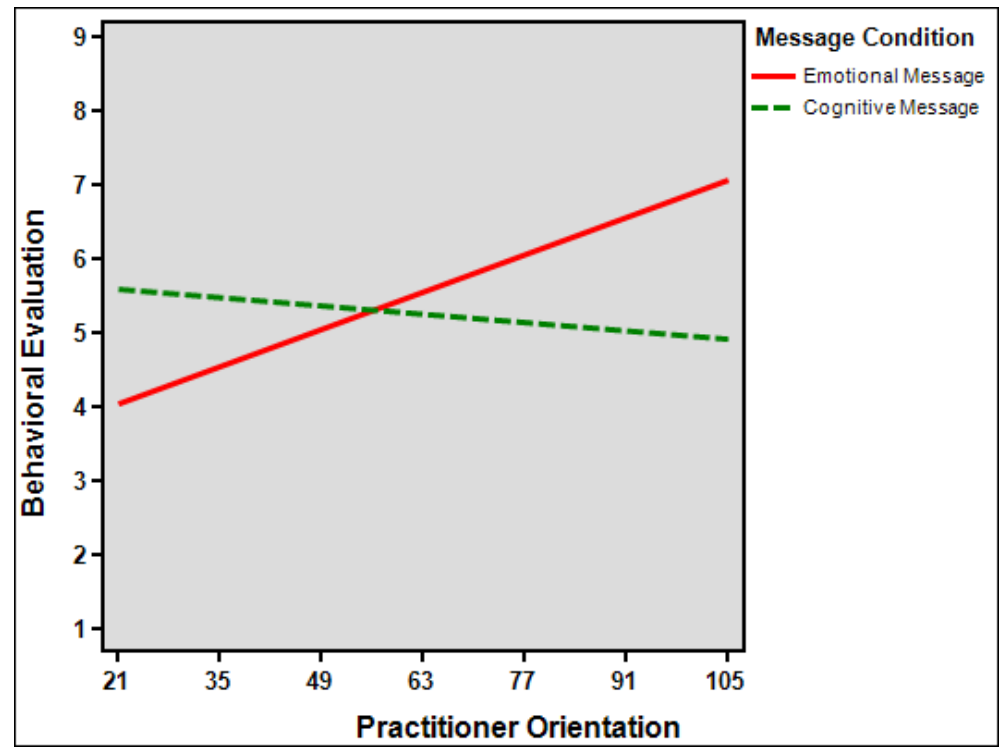

\section{Discussion}

The current study examined whether tailoring a persuasive appeal regarding a treatment to the attitude basis of the target could enhance persuasion. More specifically, it was hypothesized that individuals with a high interest in 
clinical practice would be more persuaded about the merits of a treatment when the treatment was described in emotional terms. This hypothesis was supported and is consistent with previous findings which suggest that clinicians respond more to case study material as opposed to research reports (Stewart \& Chambless, 2010). Moreover, the data suggest this may occur because individuals with a high practice orientation are more likely to expend effort and to elaborate on information that matches an affective attitude basis. This mechanism has important implications for the characteristics of the persuasive message. Specifically, if matching of attitude function and persuasive appeal produces greater elaboration or scrutiny of the message, matched messages must present a strong argument to be effective. In fact, it has been suggested that when there is a match between function and message, strong arguments produce greater attitude change; however, when the message is weak, a mismatch - resulting in less scrutiny, may be preferable (Wheeler, Petty, \& Bizer, 2005). Presumably, in practice, a strong case should be available in favor of a treatment before clinicians are encouraged to invest important resources in changing their practice; therefore, strong emotionally based messages would often be the most appropriate methods for communicating treatment advances. However, in cases in which recommendations are based on preliminary data (e.g., a promising treatment is available and the current practice produces iatrogenic effects) a matched persuasive appeal may produce high levels of scrutiny and ultimately less favorable attitudes and mismatching may be more desirable.

In the current study, we attempted to maximize the differences between our emotional and cognitive messages by using anecdotal information to present an emotionally-based case for our fictional treatment on one hand and findings from treatment outcome research to present a more cognitively based message on the other. Although it may sometimes be desirable for case studies and anecdotal data from clinical trials to be made available to clinicians, the types of findings that can be depicted in this way is somewhat limited. Moreover, ultimately it may not be desirable to attempt to close the gap between research and practice by making available a certain set of facts to clinicians and another to researchers. Fortunately, however, this may not be necessary. There is some evidence that the same exact information can be presented, regardless of the attitude function or basis, as long as the frame of the message is matched (Mayer \& Tormala, 2010). More specifically, Mayer and Tormala (2010) found matching effects when they presented participants with the same persuasive appeal but used either an "I feel" stem versus an "I think" stem to frame the message as either an emotional or cognitive appeal. Using similar procedures, clinicians could be provided with many of the nuanced findings from treatment outcome studies in a way that encourages greater processing of the data.

It is important to note that many studies examining the matching hypothesis have focused only on attitude change toward an object as the primary outcome; behavioral outcomes and attitudes toward behaviors have received little 
focus (Keer, van den Putte, \& Neijens, 2010). Although this makes some sense given the relationship between attitudes, behavioral intent, and behavior, a more direct approach is also warranted especially since some research suggests that affective messages may be more useful when changing attitudes while cognitive messages may be more useful in changing behavior and further, that this may interact with a target's predominant attitude basis (Dube \& Cantin, 2000). Therefore, examining behavioral outcomes and attitudes toward behavior is an important step in this line of research. Results examining behavioral evaluation (i.e., whether one would choose the treatment) suggest that an affective message should be superior to a cognitive one for practitioners. These results suggest that in this case attitudes and behavior may be closely linked. As such, it may be that providing emotionally based messages to practitioners could result in more favorable attitudes toward ESTs as well as changes in their clinical practice. However, since behavioral outcomes were not directly assessed in the current study, this needs to be addressed in future research. Moreover, given that several factors (e.g., attitude accessibility, Fazio \& Williams, 1986) can serve to moderate the correlation between attitudes and behavior (Petty \& Wegener, 1998), it is likely that there is a complex relationship between attitudes toward ESTs and use of ESTs.

Of note, some studies have found affectively based attitudes are held with greater confidence or certainty than cognitively based attitudes (see for example Edwards \& Vonhippel, 1995, experiment 1). Direct experience with the emotions that form the basis of an affective attitude may lead one to perceive the attitude as prima facie, without the need for outside validation. Thus, traditional views suggest that if, as we propose here, clinicians' attitudes toward ESTs have a predominantly affective basis, these attitudes would be held with a high degree of certainty and thus could prove highly resistant to change. Moreover, clinicians' attitudes toward ESTs may be held with high certainty because they likely receive extensive consensus support for such attitudes, another factor that can lead to high attitude certainty (Cialdini \& Trost, 1998; Smith \& Louis, 2009). That is, clinicians with negative attitudes toward ESTs likely work in organizations where there is some support for these attitudes given both the high prevalence of such attitudes and the decreased probability of maintaining a position when holding a view that is drastically different from the prevailing organizational opinion. Typically, attitude certainty has been viewed as a persistent barrier to persuasion. However, Clarkson and colleagues suggest an alternative hypothesis in which attitude certainty may make an attitude more or less open to change depending upon the underlying structure of the attitude (Clarkson, Tormala, \& Rucker, 2008; Clarkson et al., 2011). More specifically, Clarkson et al. (2011) hypothesized that whether certainty will amplify an attitude's openness or resistance to change is determined by message matching. When there is a match between attitude basis and persuasive message, high certainty will result in greater openness to attitude change. On the 
other hand, when there is a mismatch and the original attitude is held with high certainty, the attitude will be even more resistant to change. The two experiments they designed to test this hypothesis were largely supportive, suggesting that presenting clinicians with affective information about ESTs might result in greater openness to change not despite the certainty of these attitudes but, in part, because of it. Thus, message matching may be especially important and useful in this case.

\section{Limitations and Future Directions}

We chose to focus on a student sample likely to represent future professionals in the helping professions to provide the first test that vocational interests within the field of psychology can provide important information about the type of information that proves to be persuasive. The use of this sample is not without limitations, however. First, there is very little research examining whether student samples serve as adequate analogues for practicing mental health professionals. However, the underlying theory tested here has been shown to generalize to multiple samples, suggesting our findings may be relevant to practicing clinicians. This first test in an analogue sample, finding that vocational interests in psychology can be useful in matching persuasive messages, provides support for the future study of such an intervention in samples of mental health practitioners. Second, although we were able to ask about behavioral intentions in a hypothetical situation, we were not able to get actual behavioral measures such as change in treatment practice that could clarify whether message matching is as effective for changing behavior as it is for changing attitudes. Nevertheless, our results suggest this might be the case; therefore, future research should examine behavioral outcomes more directly.

Additionally, there is some evidence that affective and cognitive attitudes might arise from somewhat independent neurological pathways (LeDoux, 1989); thus, it may be that, at this level of analysis, the reason matched messages are more effective is because of their activation of the relevant pathways. However, to our knowledge, such a hypothesis has yet to be tested. Processing fluency and elaboration likelihood have been the primary mediating processes that have been explored, with both hypotheses receiving some support. When tested simultaneously as suggested by Preacher and Hayes (2008), we found support for elaboration but not processing fluency as a mediator of the matching effect. However, the size of the mediating effect was small so it will be important to replicate this finding and to examine other possible mediators that may be jointly responsible. A more complete understanding of the underlying mechanisms should prove useful in furthering the science of treatment dissemination. 


\section{Implications for Behavioral Health}

These findings indicate that training in empirically supported treatments provided to practicing clinicians should use a strong, affectively based argument for the use of the treatment. The exception here would be when there is some need to switch practice to a treatment with very preliminary empirical support; in this case, a relatively weak argument but one that is still affectively based should be the most persuasive. Affective information can be imparted in the type of speech that is used in an argument (using highly emotional words or tone), through message framing, or by relying primarily on experiential types of learning experiences (e.g., standardized patients). Importantly, however, it should be recognized that attitudes are just one barrier to the effective dissemination of empirically supported treatments to practicing clinicians. Research suggests that organizational characteristics and logistical barriers can serve as important predictors of engagement with empirically supported treatments (Aarons, 2005; Stewart, Chambless, \& Baron, 2012). Some of these barriers may be less relevant, however, for graduate students training to be clinicians, making these findings more relevant to student training. For example, finding time to attend a training in a particular treatment or set of treatment procedures may be difficult for a clinician balancing a full caseload and heavy paperwork demands; however, training is the primary focus of students. If faculty tailor the introduction to empirically supported treatments to the attitude basis of the students they work with this could have important implications for students' early attitudes toward these treatments and the likelihood they would use them in practice.

\section{Conclusion}

In the current study, practice-orientation was associated with a more favorable response to an affective message. Moreover, it seems that at least in part, this occurs because those with an interest in clinical activities are more likely to process and elaborate on information regarding a treatment when it is presented in affective terms. Understanding this effect and harnessing it by tailoring the way in which data are presented to clinicians could result in more positive attitudes and quicker adoption of ESTs. Pending replication, such findings suggest a relatively simple and straightforward method to help to reduce the gap between research and practice.

\section{Conflict of Interest}

The authors declare they have no conflict of interest. 


\section{References}

Aarons, G. A. (2004). Mental health provider attitudes toward adoption of evidence-based practice: The Evidence-Based Practice Attitude Scale (EBPAS). Mental Health Services Research, 6, 61-74. doi:10.1023/B:MHSR.0000024351.12294.65

Aarons, G. A. (2005). Measuring Provider Attitudes Toward Evidence-Based Practice: Consideration of Organizational Context and Individual Differences. Child and Adolescent Psychiatric Clinics of North America, 14, 255-271. doi:10.1016/j.chc.2004.04.008

Ajzen, I. (1991). The theory of planned behavior. Organizational Behavior and Human Decision Processes, 50, 179-211. doi:10.1016/0749-5978(91)90020-t

Anderson, N. H. (1971). Integration theory and attitude change. Psychological Review, 78, 171-206. doi:10.1037/h0030834

APA Presidential Task Force on Evidence-Based Practice. (2006). Evidence-based practice in psychology. American Psychologist, 61, 271-285.

Asch, S. E. (1946). Forming impressions of personality. Journal of Abnormal and Social Psychology, 41, 258-290.

Barlow, D. H., Levitt, J. T., \& Bufka, L. F. (1999). The dissemination of empirically supported treatments: A view to the future. Behaviour Research and Therapy, 37, S147-S162. doi:10.1016/s0005-7967(99)00054-6

Borntrager, C. F., Chorpita, B. F., Higa-McMillan, C. K., Daleiden, E. L., \& Starace, N. (2013). Usual care for trauma-exposed youth: Are clinician-reported therapy techniques evidence-based? Children and Youth Services Review, 35, 133-141. doi:10.1016/j.childyouth.2012.09.018

Chaiken, S., \& Trope, Y. (1999). Dual-process theories in social psychology. New York, NY US: Guilford Press.

Chambless, D. L., \& Hollon, S. D. (1998). Defining empirically supported therapies. Journal of Consulting and Clinical Psychology, 66, 7-18.

Chambless, D. L., \& Ollendick, T. H. (2001). Empirically supported psychological interventions: Controversies and evidence. Annual Review of Psychology, 52, 685716. doi:10.1146/annurev.psych.52.1.685

Chorpita, B. F., Daleiden, E. L., Ebesutani, C., Young, J., Becker, K. D., Nakamura, B. J., . . . Starace, N. (2011). Evidence-based treatments for children and adolescents: An updated review of indicators of efficacy and effectiveness. Clinical Psychology: Science and Practice, 18, 154-172. doi:10.1111/j.1468-2850.2011.01247.x

Chorpita, B. F., \& Regan, J. (2009). Dissemination of effective mental health treatment procedures: Maximizing the return on a significant investment. Behaviour Research and Therapy, 47, 990-993. doi:10.1016/j.brat.2009.07.002

Cialdini, R. B., \& Trost, M. R. (1998). Social influence: Social norms, conformity and compliance. In D. T. Gilbert, S. T. Fiske, \& G. Lindzey (Eds.), The handbook of social psychology, Vols. 1 and 2 (4th ed.). (pp. 151-192). New York, NY, US: McGraw-Hill. 
Clarkson, J. J., Tormala, Z. L., \& Rucker, D. D. (2008). A new look at the consequences of attitude certainty: The amplification hypothesis. Journal of Personality and Social Psychology, 95, 810-825. doi:10.1037/a0013192

Clarkson, J. J., Tormala, Z. L., \& Rucker, D. D. (2011). Cognitive and affective matching effects in persuasion: An amplification perspective. Personality and Social Psychology Bulletin, 37, 1415-1427. doi:10.1177/0146167211413394

de Vries, M., Witteman, C. L. M., Holland, R. W., \& Dijksterhuis, A. (2010). The unconscious thought effect in clinical decision making: An example in diagnosis. Medical Decision Making, 30, 578-581. doi:10.1177/0272989X09360820

Deacon, B. J., Farrell, N. R., Kemp, J. J., Dixon, L. J., Sy, J. T., Zhang, A. R., \& McGrath, P. B. (2013). Assessing therapist reservations about exposure therapy for anxiety disorders: The Therapist Beliefs about Exposure Scale. Journal of Anxiety Disorders, 27, 772-780. doi:10.1016/j.janxdis.2013.04.006

Deacon, B. J., Lickel, J. J., Farrell, N. R., Kemp, J. J., \& Hipol, L. J. (2013). Therapist perceptions and delivery of interoceptive exposure for panic disorder. Journal of Anxiety Disorders, 27, 259-264. doi:10.1016/j.janxdis.2013.02.004

DeRubeis, R. J., \& Crits-Christoph, P. (1998). Empirically supported individual and group psychological treatments for adult mental disorders. Journal of Consulting and Clinical Psychology, 66, 37-52. doi:10.1037/0022-006x.66.1.37

Dijksterhuis, A., \& Nordgren, L. F. (2006). A theory of unconscious thought. Perspectives on Psychological Science, 1, 95-109. doi:10.1111/j.1745-6916.2006.00007.x

Drolet, A., \& Aaker, J. (2002). Off-target? Changing cognitive-based attitudes. Journal of Consumer Psychology, 12, 59-68. doi:10.1207/s15327663jcp1201_06

Dube, L., \& Cantin, I. (2000). Promoting health or promoting pleasure? A contingency approach to the effect of informational and emotional appeals on food liking and consumption. Appetite, 35, 251-262. doi:10.1006/appe.2000.0361

Edwards, K. (1990). The interplay of affect and cognition in attitude formation and change. Journal of Personality and Social Psychology, 59, 202-216. doi:10.1037/00223514.59.2.202

Edwards, K., \& Vonhippel, W. (1995). Hearts and minds: The priority of affective versus cognitive factors in person perception. Personality and Social Psychology Bulletin, 21, 996-1011. doi:10.1177/01461672952110001

Evans, J. S. B. T. (2008). Dual-processing accounts of reasoning, judgment, and social cognition. Annual Review of Psychology, 59, 255-278. doi:10.1146/annurev.psych.59.103006.093629

Farrell, N. R., Deacon, B. J., Dixon, L. J., \& Lickel, J. J. (2013). Theory-based training strategies for modifying practitioner concerns about exposure therapy. Journal of Anxiety Disorders, 27, 781-787. doi:10.1016/j.janxdis.2013.09.003

Fazio, R. H., \& Williams, C. J. (1986). Attitude accessibility as a moderator of the attitudeperception and attitude-behavior relations: An investigation of the 1984 presidential election. Journal of Personality and Social Psychology, 51, 505-514. doi:10.1037/0022-3514.51.3.505

Gelso, C. J. (1979). Research in counseling: Methodological and professional issues. The Counseling Psychologist, 8, 7-35. 
Haddock, G., Maio, G. R., Arnold, K., \& Huskinson, T. (2008). Should persuasion be affective or cognitive? The moderating effects of need for affect and need for cognition. Personality and Social Psychology Bulletin, 34, 769-778. doi: $10.1177 / 0146167208314871$

Herek, G. M. (1987). Can functions be measured? A new perspective on the functional approach to attitudes. Social Psychology Quarterly, 50, 285-303.

Higa-McMillan, C. K., Francis, S. E., Rith-Najarian, L., \& Chorpita, B. F. (2016). Evidence base update: 50 years of research on treatment for child and adolescent anxiety. Journal of Clinical Child and Adolescent Psychology, 45, 91-113. doi:10.1080/15374416.2015.1046177

Huskinson, T. L. H., \& Haddock, G. (2004). Individual differences in attitude structure: Variance in the chronic reliance on affective and cognitive information. Journal of Experimental Social Psychology, 40, 82-90. doi:10.1016/s0022-1031(03)00060-x

IBM Corp. (Released 2016). IBM SPSS Statistics for Windows, Version 24.0 Armonk, NY: IBM Corp.

Jensen-Doss, A., Cusack, K. J., \& de Arellano, M. A. (2008). Workshop-based training in trauma-focused CBT: An in-depth analysis of impact on provider practices. Community Mental Health Journal, 44, 227-244. doi:10.1007/s10597-007-9121-8

Katz, D. (1960). The functional approach to the study of attitudes. Public Opinion Quarterly, 24, 163-204.

Keer, M., van den Putte, B., \& Neijens, P. (2010). The role of affect and cognition in health decision making. British Journal of Social Psychology, 49, 143-153. doi: $10.1348 / 014466609 \times 425337$

LeDoux, J. E. (1989). Cognitive€motional interactions in the brain. Cognition and Emotion, 3, 267-289. doi:10.1080/02699938908412709

Leong, F. T. L., \& Zachar, P. (1991). Development and validation of the Scientist-Practitioner Inventory for psychology. Journal of Counseling Psychology, 38, 331-341.

Leong, F. T. L., Zachar, P., Conant, L., \& Tolliver, D. (2007). Career speciality preferences among psychology majors: Cognitive processing styles associated with scientist and practitioner interests. The Career Development Quarterly, 55, 328-338.

Locke, B., \& Keiser-Clark, D. (2001). PsychData. State College, PA.

Lopez, M. A., Osterberg, L. D., Jensen-Doss, A., \& Rae, W. A. (2011). Effects of workshop training for providers under mandated use of an evidence-based practice. Administration and Policy in Mental Health and Mental Health Services Research, 38, 301-312. doi:10.1007/s10488-010-0326-8

Mayer, N. D., \& Tormala, Z. L. (2010). "Think" versus "Feel" framing effects in persuasion. Personality and Social Psychology Bulletin, 36, 443-454. doi:10.1177/0146167210362981

Petty, R. E., \& Cacioppo, J. T. (1981). Attitudes and persuasion: Classic and contemporary approaches. Boulder, CO: Westview Press.

Petty, R. E., \& Cacioppo, J. T. (1986). The elaboration likelihood model of persuasion. In L. Berkowitz (Ed.), Advances in Experimental Social Psychology (Vol. 19, pp. 124205). New York: Academic Press. 
Petty, R. E., \& Wegener, D. T. (1998). Matching versus mismatching attitude functions: Implications for scrutiny of persuasive messages. Personality and Social Psychology Bulletin, 24, 227-240. doi:10.1177/0146167298243001

Petty, R. E., \& Wegener, D. T. (1999). The Elaboration Likelihood Model: Current status and controversies. In S. Chaiken \& Y. Trope (Eds.), Dual-process theories in social psychology. (pp. 37-72). New York, NY: Guilford Press.

Preacher, K. J., \& Hayes, A. F. (2008). Asymptotic and resampling strategies for assesing and comparing indirect effects in multiple mediator models. Behavior Research Methods, 40, 879-891.

Seligman, L. D., Hovey, J. D., Hurtado, G., Swedish, E. F., Roley, M. E., Geers, A. L., . . . Ollendick, T. H. (2016). Social cognitive correlates of attitudes toward empirically supported treatments. Professional Psychology: Research and Practice, 47, 215-223. doi: $10.1037 /$ pro0000068

Smith, J. R., \& Louis, W. R. (2009). Group norms and the attitude-behaviour relationship. Social and Personality Psychology Compass, 3, 19-35. doi:10.1111/j.17519004.2008.00161.x

Stewart, R. E., \& Chambless, D. L. (2007). Does psychotherapy research inform treatment decisions in private practice? Journal of Clinical Psychology, 63, 267-281. doi: $10.1002 /$ jclp. 20347

Stewart, R. E., \& Chambless, D. L. (2010). Interesting practitioners in training in empirically supported treatments: Research reviews versus case studies. Journal of Clinical Psychology, 66, 73-95.

Stewart, R. E., Chambless, D. L., \& Baron, J. (2012). Theoretical and practical barriers to practitioners' willingness to seek training in empirically supported treatments. Journal of Clinical Psychology, 68, 8-23.

Strack, F., \& Deutsch, R. (2004). Reflective and Impulsive Determinants of Social Behavior. Personality and Social Psychology Review, 8, 220-247. doi:10.1207/s15327957pspr0803_1

Wheeler, S. C., Petty, R. E., \& Bizer, G. Y. (2005). Self-schema matching and attitude change: Situational and dispositional determinants of message elaboration. Journal of Consumer Research, 31, 787-797. doi:10.1086/426613

Wilson, T. D., \& Dunn, D. S. (1986). Effects of introspection on attitude-behavior consistency: Analyzing reasons versus focusing on feelings. Journal of Experimental Social Psychology, 22, 249-263.

Zajonc, R. B., \& Markus, H. (1982). Affective and cognitive factors in preferences. Journal of Consumer Research, 9, 123-131. 

Copyright of Journal of Evidence-Based Psychotherapies is the property of International Institute for the Advanced Studies of Psychotherapy \& Applied Mental Health and its content may not be copied or emailed to multiple sites or posted to a listserv without the copyright holder's express written permission. However, users may print, download, or email articles for individual use. 